\section{Molecular Profiling Is Rather Likely to Be Cost Effective}

To THE EDITOR: In a recent report, Bonastre et $\mathrm{al}^{1}$ calculated the cost effectiveness of molecular profiling for adjuvant decision making in patients with node-negative breast cancer and concluded that, under the present circumstances in France, the 70-gene signature (MammaPrint) is unlikely to be cost effective.

We believe that there are two main aspects of the article that deserve a rebuttal, especially given that one of our articles is mentioned in the discussion. ${ }^{2}$ Bonastre et $\mathrm{al}^{1}$ state that our group made assumptions that were in favor of the 70-gene signature. ${ }^{2,3}$ However, these assumptions were all evidence based and published in peer-reviewed journals - although, of course, they were based on the Dutch health care system. One issue in the article by Bonastre et al is that the costs of chemotherapy as shown seem low. This is probably because of the type of third-generation adjuvant chemotherapy regimen that was chosen. Although a direct comparison is lacking, the three cycles of fluorouracil-epirubicin-cyclophosphamide followed by three cycles of docetaxel (T) is likely to be the least effective third-generation regimen, albeit the cheapest. On the basis of recent evidence ${ }^{4,5}$ and European Union recommendations ${ }^{6}$ or US National Comprehensive Cancer Network guidelines, ${ }^{7}$ preferable treatment regimens include doxorubicin-cyclophosphamide (AC) once every 3 weeks for four cycles, followed by T once every 3 weeks for four cycles, or TAC once every 3 weeks for six cycles, both with pegfilgrastim for four to six cycles (administered subcutaneously). ${ }^{4}$ Furthermore, AC once every 2 weeks for four cycles with pegfilgrastim, followed by paclitaxel once every 2 weeks for four cycles with pegfilgrastim, is equal to six cycles of TAC with pegfilgrastim. ${ }^{5}$ Moreover, according to the European Union recommendations, all of these regimens, including three cycles of fluorouracil-epirubicin-cyclophosphamide/three cycles of T, require pegfilgrastim. ${ }^{6}$ This will substantially raise the total chemotherapy costs. The estimated cost of providing pegfilgrastim to every highrisk patient receiving a taxane-based regimen is $5 \times € 1,100,{ }^{8}$ which amounts to $€ 5,500$ instead of the $€ 749$ reported by Bonastre et al, who estimated that pegfilgrastim would be given to $22 \%$ of the high-risk patients. Subsequently, it is known that in the node-negative breast cancer population, $10 \%$ of patients have a human epidermal growth factor receptor $2 / n e u$-positive tumor; of this $10 \%, 78 \%$ are in the high-risk group. ${ }^{9}$ This means that use of trastuzumab should also be taken into account, even if for only a small percentage of patients, resulting in high costs per patient of approximately $€ 35,000,{ }^{3}$ an amount that excludes additional costs for adverse events such as cardiotoxicity. In Table 1 of the article by Bonastre et al, it was unclear how many office visits were included in the chemotherapy cost calculation or exactly how the survival probabilities were estimated; therefore, it was difficult for us to reproduce the entire analysis. However, if the additional costs already discussed (a total of approximately $€ 4,751)$ are added to the presented total chemotherapy price ( $€ 4,751$ plus $€ 7,486$ amounts to $€ 12,237$ per patient), the conclusion will be totally different. Finally, it is expected that the costs for (early) breast cancer will increase in the coming years, for example, as targeted therapies are applied.

The most important objective of the 70-gene signature (or any other comparable genomic array) is to personalize treatment and reduce unnecessary adjuvant chemotherapy use, thereby avoiding unnecessary toxicity; if there is already significantly less chemotherapy and/or trastuzumab use and/or low costs of chemotherapy, then it is inevitable that gene array testing is not likely to be cost effective. Apparently, in France, costs of chemotherapy are low, and the preferred chemotherapy regimen differs from the preferred regimens in the US and the Netherlands. We therefore disagree that the conclusion presented by Bonastre et $\mathrm{al}^{1}$ would hold true for the Netherlands or the United States, where other chemotherapy regimens are used and average treatment costs are higher.

Bonastre et $\mathrm{al}^{1}$ correctly point out that it is necessary to closely scrutinize national circumstances concerning the various treatment parameters, including the pricing of the molecular profile under study, before drawing conclusions about cost effectiveness. In the near future, additional molecular profiles or techniques using next/whole-generation sequencing will enter the market at a lower price. Assuming that molecular profiling will outperform Adjuvant! Online and the existing guidelines for selecting the right patients for the right treatment, it is still likely that the trade-off between costs and outcomes will ultimately be of benefit for the individual patient.

\section{Valesca P. Retèl}

Netherlands Cancer Institute, Amsterdam, the Netherlands

\section{Sabine C. Linn}

Netherlands Cancer Institute, Amsterdam; and University Medical Center Utrecht, Utrecht, the Netherlands

\section{Wim H. van Harten}

Netherlands Cancer Institute, Amsterdam; and University of Twente, School of Governance and Management, Enschede, the Netherlands

\section{ACKNOWLEDGMENT}

We thank Harry Bartelink, MD, $\mathrm{PhD}$, for his thorough review of this correspondence.

\section{AUTHORS' DISCLOSURES OF POTENTIAL CONFLICTS OF INTEREST}

Disclosures provided by the authors are available with this article at www.jco.org.

\section{REFERENCES}

1. Bonastre J, Marguet S, Lueza B, et al: Cost effectiveness of molecular profiling for adjuvant decision making in patients with node-negative breast cancer. J Clin Oncol 32:3513-3519, 2014

2. Retèl VP, Joore MA, Knauer M, et al: Cost-effectiveness of the 70-gene signature versus St. Gallen guidelines and Adjuvant Online for early breast cancer. Eur J Cancer 46:1382-1391, 2010

3. van't Veer LJ, Dai H, van de Vijver MJ, et al: Gene expression profiling predicts clinical outcome of breast cancer. Nature 415:530-536, 2002

4. Eiermann W, Pienkowski T, Crown J, et al: Phase III study of doxorubicin/ cyclophosphamide with concomitant versus sequential docetaxel as adjuvant 
treatment in patients with human epidermal growth factor receptor 2-normal, node-positive breast cancer: BCIRG-005 trial. J Clin Oncol 29:3877-3884, 2011

5. Swain SM, Tang G, Geyer CE Jr, et al: Definitive results of a phase III adjuvant trial comparing three chemotherapy regimens in women with operable, node-positive breast cancer: The NSABP B-38 trial. J Clin Oncol 31:3197-3204, 2013

6. Aapro MS, Bohlius J, Cameron DA, et al: 2010 update of EORTC guidelines for the use of granulocyte-colony stimulating factor to reduce the incidence of chemotherapy-induced febrile neutropenia in adult patients with lymphoproliferative disorders and solid tumours. Eur J Cancer 47:8-32, 2011
7. National Comprehensive Cancer Network: NCCN Clinical Practice Guidelines in Oncology: Breast cancer. Version 3.2014. www.nccn.org

8. Zorginstituut Nederland: Pharmaceutical costs derived from the government Web site [in Dutch]. www.medicijnkosten.nl

9. Knauer $\mathrm{M}$, Cardoso $\mathrm{F}$, Wesseling $\mathrm{J}$, et al: Identification of a low-risk subgroup of HER-2-positive breast cancer by the 70-gene prognosis signature. $\mathrm{Br}$ J Cancer 103:1788-1793, 2010

DOI: 10.1200/JCO.2014.59.8029; published online ahead of print at www.jco.org on April 6, 2015 


\section{AUTHORS' DISCLOSURES OF POTENTIAL CONFLICTS OF INTEREST}

\section{Molecular Profiling Is Rather Likely to Be Cost Effective}

The following represents disclosure information provided by authors of this manuscript. All relationships are considered compensated. Relationships are self-held unless noted. I = Immediate Family Member, Inst = My Institution. Relationships may not relate to the subject matter of this manuscript. For more information about ASCO's conflict of interest policy, please refer to www.asco.org/rwc or jco.ascopubs.org/site/ifc.

\section{Valesca P. Retèl}

No relationship to disclose

\section{Sabine C. Linn}

Consulting or Advisory Role: Roche (Inst)

Research Funding: Roche/Genentech (Inst)

Patents, Royalties, Other Intellectual Property: Sabine C. Linn is a named inventor on the BRCA1-like test for predicting response to anticancer treatment (Inst)

Travel, Accommodations, Expenses: Roche

\section{Wim H. van Harten}

Other Relationship: Agendia 